\title{
Role of MRUrethrography Compared to Conventional Opposing Urethrographyin the Surgical Management of ObliterativePosterior Urethral Stricture
}

\author{
Dr.V.Sudhakar MD,RD ${ }^{1}$, Dr. S.Senthil Kumar DM,RD ${ }^{2}$, \\ ${ }^{1}$ Senior Assistant Professor OfRadiology, Government Kilpauk Medical College, Chennai. \\ ${ }^{2}$ Senior Resident Of Radiology, Government Kilpauk Medical College, Chennai.
}

\begin{abstract}
Objective: To prospectively assess the role of MR urethrography compared to conventional opposing urethrography in the surgical management of obliterativeposterior urethral stricture.

Materials And Methods: 18 male patients along with 2 controls in the age group of 20-65, who presented to the radiology department with symptoms of urinary retention and in whom conventional opposing urethrography (OUG) had been performed were taken up for study.MR urethrography (MRU)was performed in these patients after a time interval of about 4 to 10 days, were analysed and it was focussed on location, number, length and the signal intensity of the stricture. Urethral stricture is measured along the long axis of the fibrotic segment shown as low signal intensity on the sagittal T2-weighted images.

Posterior urethral stricture is determined to be the distance between the proximal limit of the distal distended urethra and the prostatic apex on the sagittal T2-weighted images. Stricture length onOUG was determined by measuring the distance between the proximal end of the distal distended urethra and the distal end of the open proximal urethra.Strictures with length of $<2.5$ were defined as "short strictures", where as those $>2.5$ as "long strictures". Additionally, MR findings were evaluated with regard to the urethra proximal to the stricture, the corpora spongiosa surrounding the stricture, adjacent organ injuries, and the associated complications like prostatic apex displacement, fistulas, sinus tracts etc.,

Results And Analysis: Paired T test correlations was performed to correlate the imaging and surgical length of stricture. The mean measurement errors between the imaging and surgical values of stricture length were calculated in each imaging method.MRU proved to be $100 \%$ sensitive and specific comparedto opposing urethrographywith a sensitivity and specificity of $22 \%, 70 \%$ for posterior urethral strictures.

Conclusion: MR Urethrography using T2 weighted sequences can be a valuable means of imaging patients with posterior urethral strictures as well as rest of urinary system.From our study, it is evident that MRU depicts stricture length, periurethral fibrosis, displacement of the prostatic apex and also associated pathologies with accuracy, there by assisting the surgeons to the select most appropriate surgical procedure for the patients with obliterative urethral stricture.
\end{abstract}

Keywords:

MRU MR Urethrography

OUG Opposing Urethrography

HASTEHalf Fourier Acquisition of Single Shot Turbo Spin Echosequences

$\boldsymbol{R A R E R a p i d ~ a c q u i s i t i o n ~ w i t h ~ r e l a x a t i o n ~ e n h a n c e m e n t ~}$

Posterior urethral stricture

Sagittal T2 weighted image.

Periurethral fibrosis

Prostatic apex displacement, fistulas, sinus tracts etc.

Roof of the penile bulb

\section{Introduction}

Imaging of the urinary tract with radiographs and contrast media played important role in the diagnosis of disorders of urinary tract for decades. The first ever retrograde pyelogram was done by VoelckerF,Von Lichtenberg (1). Intravenous urography gives a good anatomic detail of the urinary system and provides semi quantitative details about the renal function. Ascending or retrogradeurethrography and opposing urethrography are considered the investigations of choice to image urethra.

\subsection{Opposing Urethrography}

It is a combination technique of retrograde urethrogram (2) and voiding cystourethrogram. In cases of posterior urethral stricture, OUG is the preferred technique to measure the length of stricture. $300-400 \mathrm{ml}$ of iodinated 
contrast mixed with normal saline instilled in to the bladder via a suprapubiccystostomy catheter. Then images were taken in 30 degree, right or left anterior oblique positions, while the anterior urethra is injected with contrast and the patient asked to strainunder fluoroscopic guidance.

\section{Image analysis}

Full length of urethra is viewed for narrowing mucosal irregularities, any fistulas sinus tracts. The stricture length is measured between the tapered ends.

\section{Limitations of study}

The length of the stricture involving posterior urethra is grossly overestimated by this modality. It also causes $0.5-1.6 \%$ of infections. There is risk of allergic reactions due to contrast, radiation exposure to testis (5-9 msv), equal 230 chest radiographs. It does not give information about the extent of periurethral fibrosis. Intravasation of contrast can occur if excessive pressure is given to when injecting the contrast to overcome a stricture. Also urethral spasm may sometime occur which hinders the assessment of urethral pathology.

\subsection{MRUrethrography}

In imaging of the urethra Magnetic resonance imaging (MRI)is an excellent alternative tool. It is possible to rapidly acquire images of the urethra which are more informative than OUG even without the administration of contrast media with the RARE (Rapid acquisition with relaxation enhancement) and HASTE (Half Fourier Acquisition of Single Shot Turbo Spin Echo) sequences. This can overcome many of the drawbacks associated with OUG. With few of its drawbacks, MRU(3,4), can be done to study the abnormalities of the urethra in a variety of situations, successfully.This study is an attempt to study the diagnostic capability and efficacy of MRU, in the visualization of the posterior urethra in comparison to OUG andmost importantlyits role in providing the information required by the surgeon to plan the most appropriate surgical procedure.

\section{Materials And Methods}

18 male patients along with 2 controls in the age group of 20-65, who presented to the radiology department with symptoms of urinary retention and in whom OUG had been performed were taken up for study. The study was performed in SIEMENS MAGNETOM Symphony 1.5 Tesla MRI scanner available at our institute.

HASTE sequence was obtained in each patient using a torso pelvic phased array coil, as described below.

Period of study : 3 Years

\subsection{Inclusion Criteria}

\section{Cases}

18 male patients in the age group of 20-65 years with history of pelvic bone fracture or radical prostatectomy presenting with symptoms of urethral stricture andpatients in whom OUGhas been done for suspected urethral stricture. After a time interval of about 4 to 10 days,MRU was performed in these patients.

\section{Controls}

2male patients who underwent screening for symptoms of urethral stricture for whom MRU is normal.

\subsection{Exclusion Criteria}

Patients with metallic implants like cardiac pacemaker, implanted cardiac defibrillator, cochlear implants etc., severe hypersensitivity or previous allergic reactions, claustrophobia critically ill patients.

\begin{tabular}{lcl}
\multicolumn{2}{l}{ HASTE Sequence } \\
Slices & $:$ & 15 \\
FOV read & $:$ & $300 \mathrm{~mm}$ \\
FOV phase & $:$ & 100 \\
Slice thickness & $:$ & $2 \mathrm{~mm}$ \\
TR & $:$ & $4000-6000 \mathrm{~ms}$ \\
TE & $:$ & $80-120 \mathrm{~ms}$ \\
Averages & $:$ & 1 \\
Flip angle & $:$ & 150 \\
Turbo factor & $:$ & 218 \\
Echo spacing & $:$ & $8 \mathrm{~ms}$
\end{tabular}

Patient preparation: No specific preparation. 
Patient position: Head first and supine.

\subsection{Procedure}

\section{MRUrethrography}

Patient is placed in Torso pelvic phased array coil.Initially, 150-300 $\mathrm{ml}$ of normal saline was infused slowly into the emptied bladder through the suprapubic cystostomy catheter until the patient felt the need to void. The tip of a $10 \mathrm{ml}$ syringe filled with $8-10 \mathrm{ml}$ of sterile lubricating gel was inserted into the external urethral meatus. The sterile lubricating jelly was infused in to the anterior urethra until resistance was felt and some of the lubricating jelly overflowed from the urethral meatus. The glans sulcus of the penis was then gently tied by using long gauze in order to avoid escape of the lubricating jelly. The penile shaft was secured in the midsagittal position of the pelvis by using an upward traction and taping the edges of the tying gauze to the abdomen.High resolution sagittal T2 weighted images of penis and bladder was acquired. Coronal and axial images were also obtained. The center of the localizer was placed over the symphysis to cover the bladder and urethra.Patient was then asked to strain and images were again obtained during straining in an attempt to open the bladder neck.

\subsection{Image Analysis}

\section{MRU}

Obtained images were analysed and it was focussed on location, number, length and the signal intensity of the stricture in MRU.

Posterior urethral stricture is determined to be the distance between the proximal limit of the distal distended urethra and the prostatic apex on the sagittal T2-weighted images.Additionally, MR findings were evaluated with regard to the urethra proximal to the stricture, the corpora spongiosa surrounding the stricture, adjacent organ injuries, and the associated complications like prostatic apex displacement, fistulas, sinus tracts etc.,

Extent of periurethral fibrosis was assessed by characterizing the surrounding depth and hypointensity of periurethral tissue.

Assessment of prostatic apex displacement: Superior to inferior displacement is measured between prostatic apex and inferior pubic ramus of $>1 \mathrm{~cm}$ is considered significant.

Antero posterior displacement is the distance between apex of prostate and insertion of urethra at the roof of the penile bulb.

Lateral displacement is the distance between prostatic apex and bulbous urethra on the coronal image.

\subsection{Conventional opposing urethrography (OUG)}

Stricture length onOUG was determined by measuring the distance between the proximal end of the distal distended urethra and the distal end of the open proximal urethra.

Strictures with length of $<2.5$ were defined as "short strictures", where as those $>2.5$ as "long strictures".

III. Representative Images

Fig.1 Normal anatomy of the male urethra.

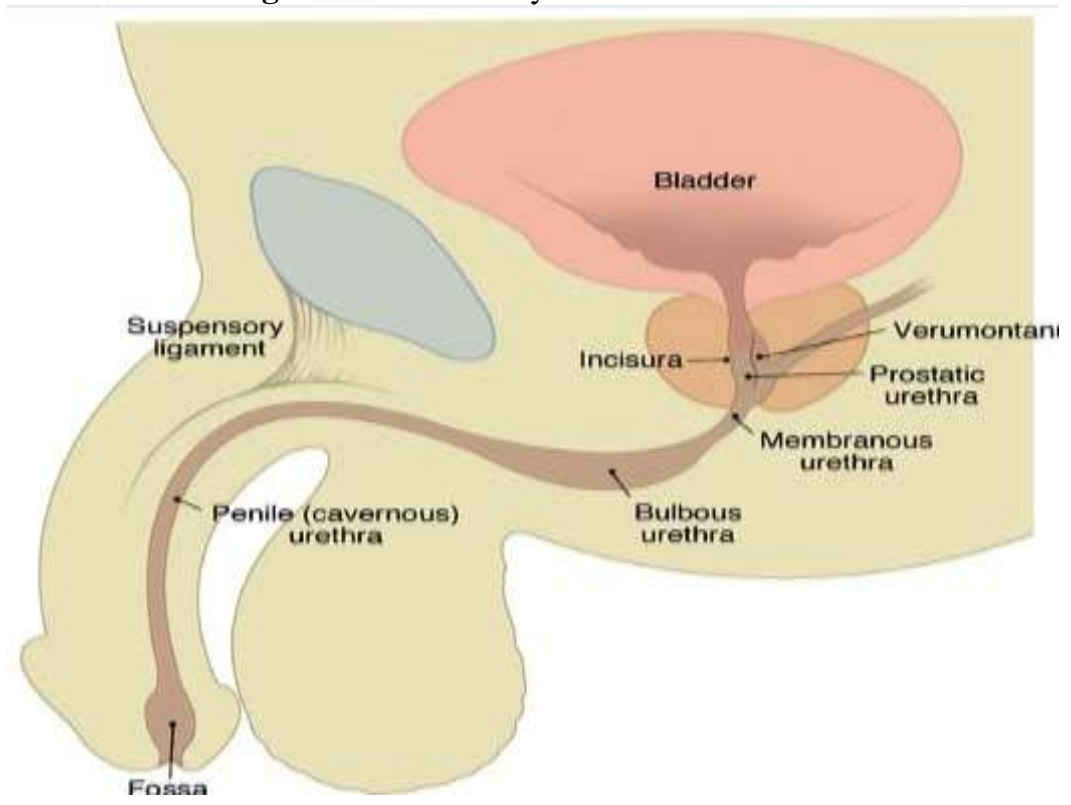

3.1. Case. 1 


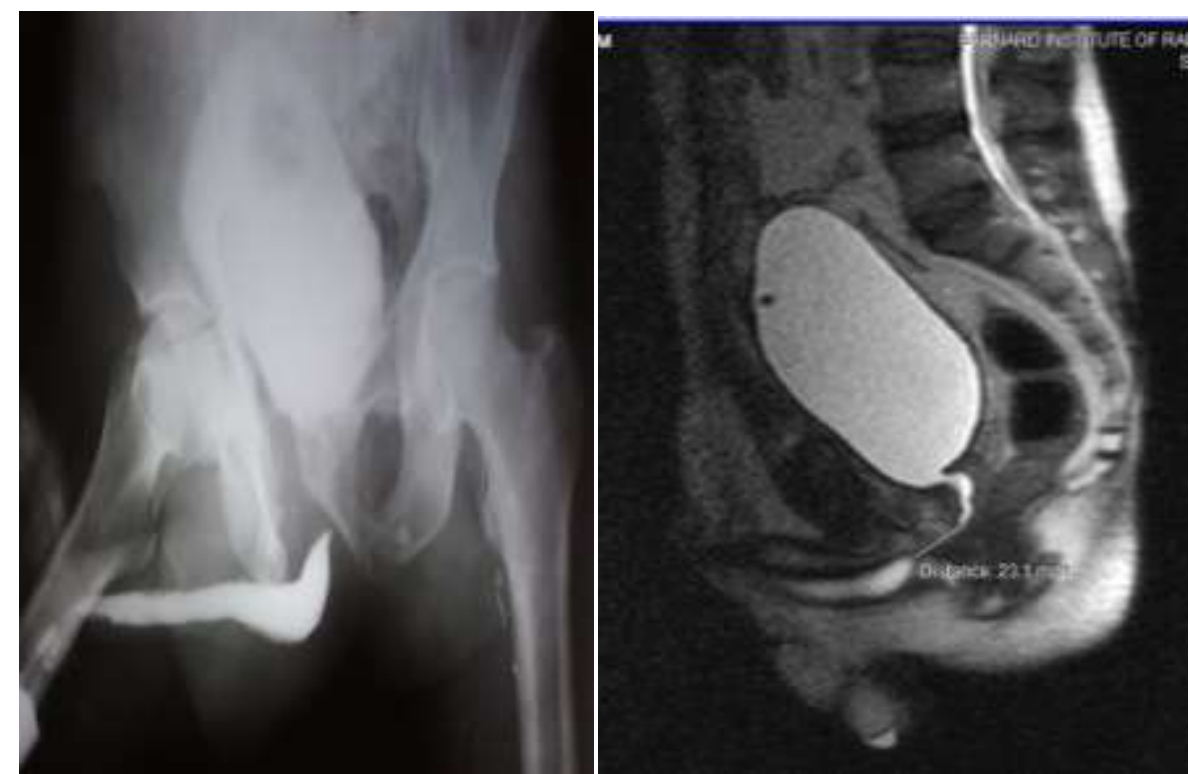

42 years old patient with history of inability to pass urine following pelvic bone fracture. OUG overestimated the length of posterior urethral stricture as determined by the distance from the bladder neck to the proximal end of the distal dilated urethra. Whereas MRU depicted the accurate stricture length as shown by hypointense signal between the proximal limit of the distal distended urethra and the prostatic apex on the sagittal T2-weighted HASTE images.

\subsection{CASE.2}
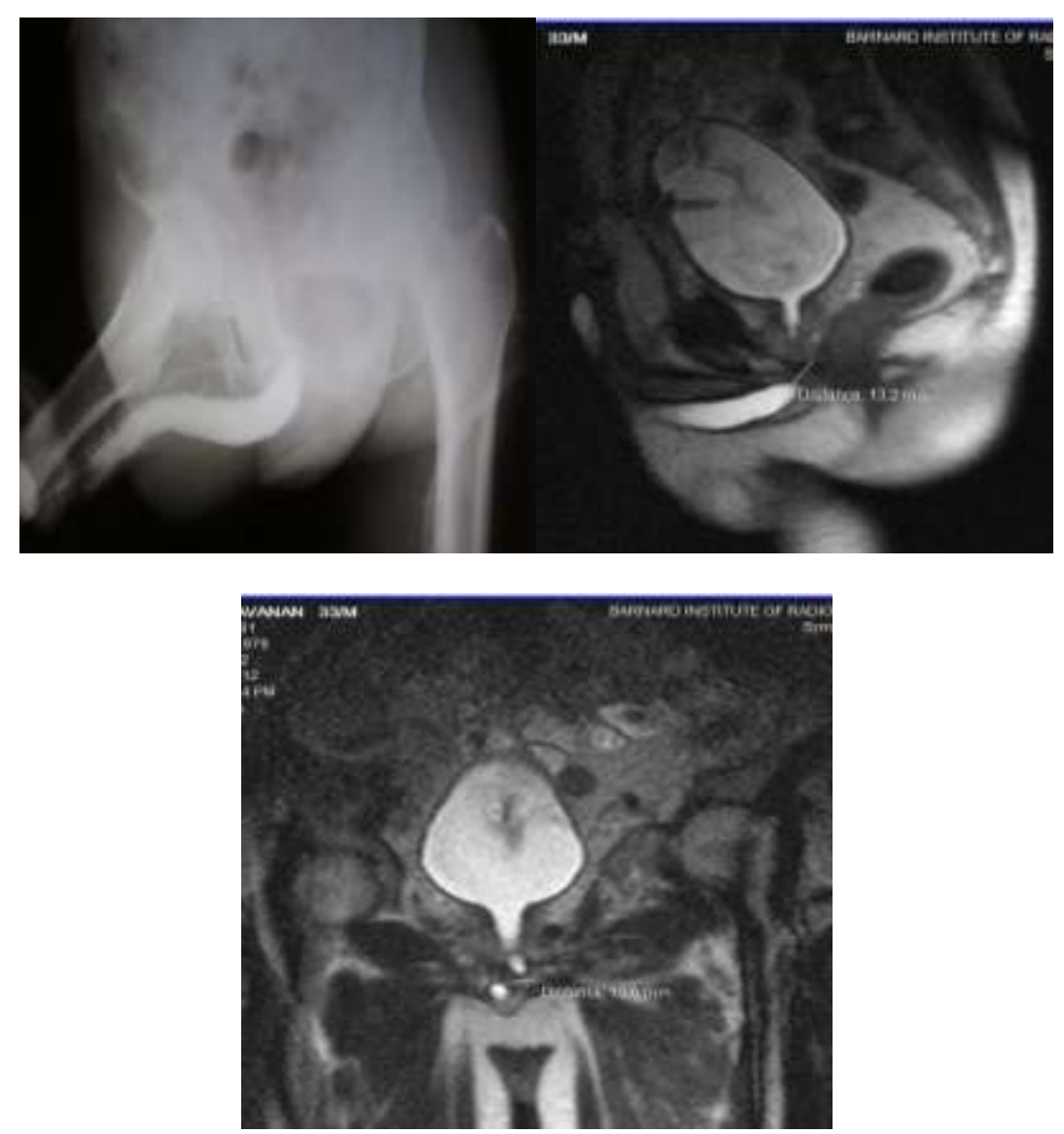
33years old patient with history of inability to pass urine following pelvic bonefracture.OUG overestimated the length of posterior urethral stricture. MRU showed the accurate stricture length and the prostatic apex displacement on sagittal and coronal HASTE images respectively.

\subsection{Case.3}
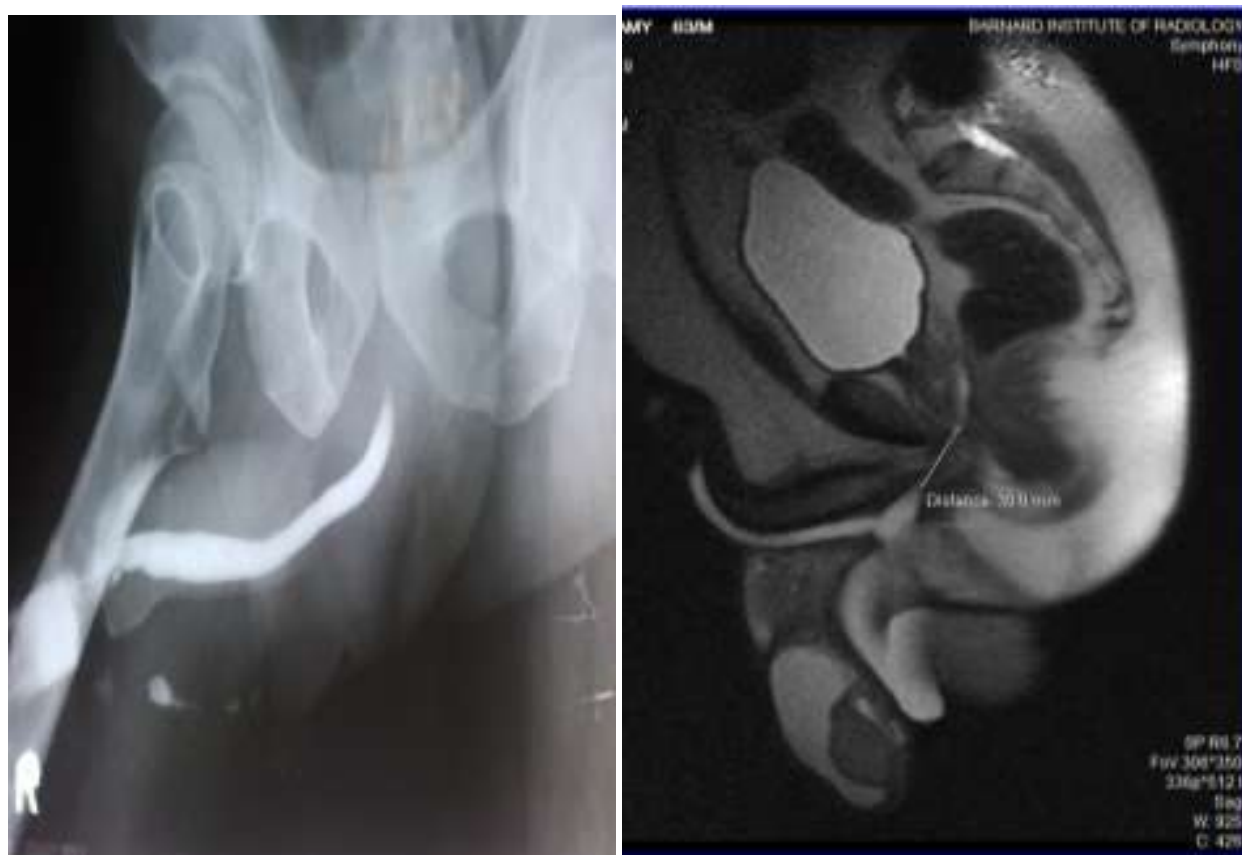

64 years old patient with history of inability to pass urine following pelvic bone fracture. OUG overestimated the length of posterior urethral stricture.MRU showed accurate stricture length,periurethral fibrosis, fistulous track communicating scrotal abscess with bulbar urethra and hydrocele.

\subsection{Case.4}
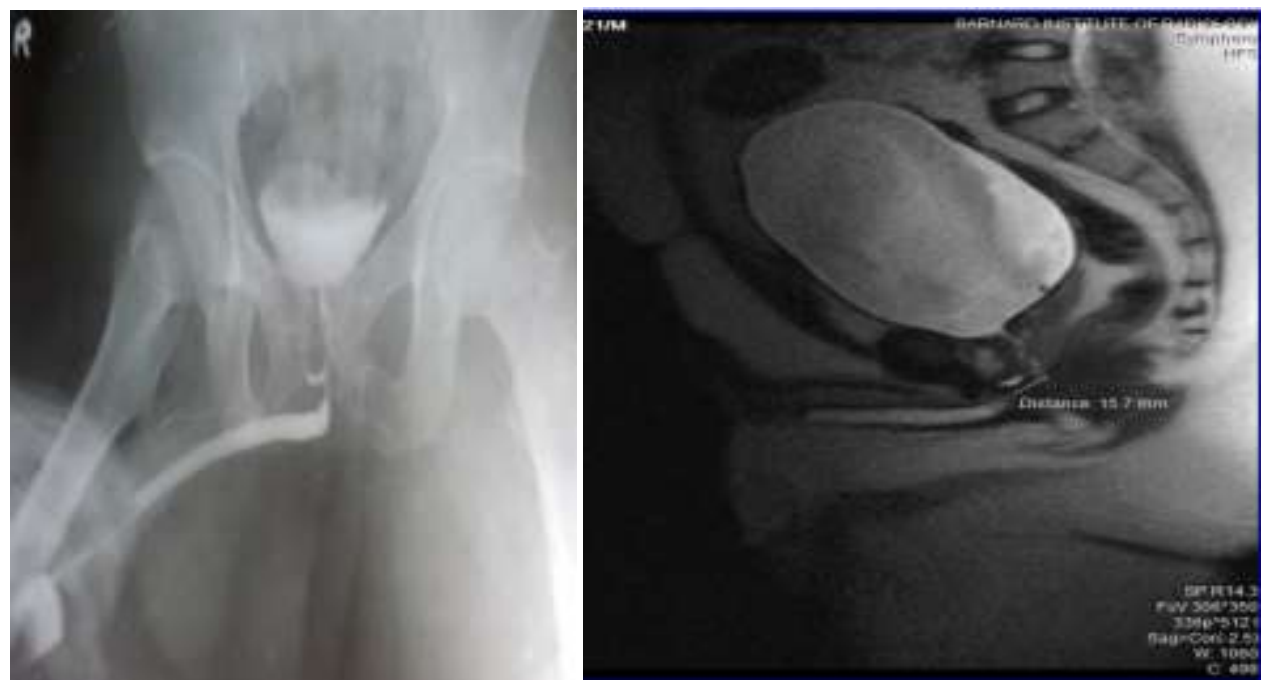

21 years old patient with history of inability to pass urine following pelvic bone fracture. OUG is inconclusive about the length of posterior urethral stricture. MRU showed the stricture length,extensive periurethral fibrosis and a short blind ending sinus tract arising from the proximal prostatic urethra.

\section{Results}

Initially planned the surgical procedure according to conventional opposing urethrography findings, then changed, based on MRU findings. The results of each imaging method were compared with a description of the surgical findings. 


\subsection{Surgical Procedures}

Endoscopic internal urethrotomy $-0.5-1.5 \mathrm{~cm}$.

Primary anastomotic urethroplasty by a perineal approach up to $2.5 \mathrm{~cm}$.

Complex urethroplasty - more than $2.5 \mathrm{~cm}$.

\subsection{Statistical Analysis}

Table.1Group Statistics

\begin{tabular}{|l|l|l|l|l|l|}
\hline & Stricture & $\mathrm{N}$ & Mean & Std. Deviation & $\begin{array}{l}\text { Std. Error } \\
\text { Mean }\end{array}$ \\
\hline $\begin{array}{l}\text { Conventional OUG - } \\
\text { Length }\end{array}$ & Posterior & 18 & 3.808 & 1.2859 & .3712 \\
\hline $\begin{array}{l}\text { MR Urethrography - } \\
\text { Length }\end{array}$ & Posterior & 18 & 2.150 & .9376 & .2707 \\
\hline Surgical length & Posterior & 18 & 2.308 & 1.0220 & .2950 \\
\hline
\end{tabular}

Paired $\mathrm{T}$ test correlations was performed to correlate the imaging and surgical length of stricture. The standard mean measurement errors and standard deviation between the imaging and surgical values of stricture length were calculated in each imaging method.

Table.2T-Test - Posterior urethral strictures Paired Samples Statistics

\begin{tabular}{|c|c|c|c|c|c|c|}
\hline & & Mean & $\mathrm{N}$ & Std. Deviation & $\begin{array}{l}\text { Std. Error } \\
\text { Mean }\end{array}$ & $\mathrm{P}$ value \\
\hline \multirow[t]{2}{*}{ Pair 1} & $\begin{array}{ll}\text { Conventional OUG- } \\
\text { Length }\end{array}$ & 3.808 & 18 & 1.2859 & .3712 & \multirow[t]{2}{*}{.001} \\
\hline & $\begin{array}{l}\text { MR Urethrography - } \\
\text { Length }\end{array}$ & 2.150 & 18 & .9376 & .2707 & \\
\hline \multirow[t]{2}{*}{ Pair 2} & $\begin{array}{ll}\text { Conventional OUG- } \\
\text { Length }\end{array}$ & 3.808 & 18 & 1.2859 & .3712 & \multirow[t]{2}{*}{.001} \\
\hline & Surgical length & 2.308 & 18 & 1.0220 & 2950 & \\
\hline \multirow[t]{2}{*}{ Pair 3} & $\begin{array}{l}\text { MR Urethrography - } \\
\text { Length }\end{array}$ & 2.150 & 18 & 9376 & .2707 & \multirow[t]{2}{*}{.055} \\
\hline & Surgical length & 2.308 & 18 & 1.0220 & 2950 & \\
\hline
\end{tabular}

A $\mathrm{P}$ value $<.05$ is considered to indicate a significant difference

Table.3Paired Samples Correlations

\begin{tabular}{|l|l|r|r|r|}
\hline \multicolumn{2}{|l|}{} & $\mathrm{N}$ & \multicolumn{1}{|c|}{ Correlation } & \multicolumn{2}{c|}{ P value } \\
\hline Pair 1 & $\begin{array}{l}\text { Conventional OUG - Length \& } \\
\text { MR Urethrography - Length }\end{array}$ & 18 & .828 & .001 \\
\hline Pair 2 & $\begin{array}{l}\text { Conventional OUG - Length \& } \\
\text { Surgical length }\end{array}$ & 18 & .795 & .001 \\
\hline Pair 3 & $\begin{array}{l}\text { MR Urethrography - Length \& } \\
\text { Surgical length }\end{array}$ & 18 & .973 & \\
\hline
\end{tabular}

A $\mathrm{P}$ value $<.05$ is considered to indicate a significant difference

\section{Discussion}

Strictures with length of $<2.5 \mathrm{~cm}$ were defined as "short strictures", whereas $>2.5 \mathrm{~cm}$ as "long strictures".There are many treatment options for obliterative urethral strictures. The optionschosen depends on several factors, most important being the stricture length(5). Endoscopic treatment can be useful for a thin septum like stricture $0.5-1.5 \mathrm{~cm} \mathrm{(6).} \mathrm{A} \mathrm{short} \mathrm{urethral} \mathrm{stricture} \mathrm{measuring}<2.5 \mathrm{~cm}$, is amenable to be managed with primary anastomotic urethroplasty $(7,8)$. Whereas a complex technique involving a graft or flap is generally performed in patients with a long urethral strictures measuring $>2.5 \mathrm{~cm}$. (9)Primary anastomotic urethroplasty is mainly done by the perineal route. The transpubic approach is done for long strictures associated with fistulous tracts, cavities in the periurethral region or opened bladder neck. $(10,11)$

The other factors that determine the choice of repair include the stricture causes, the extent of fibrosis of the corpora spongiosa, prior surgical treatment and the surgeon's option. Therefore a careful evaluation of the obliterative urethral stricture is most important in the surgical management.OUG is the method of choice among investigative procedures for the planning of a urethral reconstruction.(12) This technique, however it cannot provide an accurate measurement of the stricture length because of the poor prostatic urethral filling and 
provides no information regarding periurethral fibrosis or displacement of the prostate. A stricture length could be overestimated if the bladder neck does not relax.(13)

The extent of the stricture can be determined if the patient opens the bladder neck. But it is only rarely possible, because the will be in long term suprapubic catheterisation to allow urinary diversion which causes reduced bladder capacity. For the same reason the patient may not be able tolerate bladder distension which is sufficient enough to voluntarily open the bladder neck.(14)

In an attempt to open the bladder neck, failure to demonstrate the prostatic urethra by no means imply a bladder neck obstruction or an urethral stricture is present right up to the level of bladder neck.(15).

In this regard in order to identify the proximal limit of the stricture, a metal sound can be introduced via the suprapubiccystostomy track to accommodate the indwelling suprapubic catheter into the bladder, down through the bladder neck. However it is a cumbersome procedure associated with complications such as severe pain and hematuria resulting from bladder neck injury.

\section{Conclusion}

OUG were well known established technique in delineating posterior urethral strictures. These modalities although readily available and cost effective do not determine the accurate length andperiurethral fibrosis. Furthermore, if the patient cannot relax the bladder neck the length of stricture can be grossly overestimated in a case of posterior urethral stricture. These studies also requires adequate degrees of renal function for contrast excretion, the need for administration of potentially risk contrast media, the relatively significant amount of radiation exposure especially in younger patients.

MRU can be a valuable means of imaging patients with urethral strictures. T2 weighted sequences are excellent for demonstrating urethra as well as rest of urinary system. MR imaging is especially useful in planning the surgical procedure in cases of posterior urethral strictures with displacement the prostatic apex due to pelvic trauma. It also determines the avulsion of corpus cavernosumfrom the ischaemia which result in impotence. It accurately shows the stricture length and prostatic apical displacement and dictates the surgeon to plan the surgery via the perineal (or) transpubic approach. A combined perineal and transpubic approaches may be needed in larger defects measuring more than $6 \mathrm{~cm}$ with extensive suprolateral displacement. In this condition only strictures upto $1.5 \mathrm{~cm}$ are amenable for endoscopic urethrotomy. Even with these short strictures extensive periurethral fibrosis preclude dilatations and endoscopic urethrotomy requiring primary anastomotic urethroplasty.

MRU can be successfully performed in patients in whom contrast studies are contraindicated. Paediatric population can also be subjected to MRU without radiation to testis.

From our study, it is evident that MRU depicts stricture length, periurethral fibrosis, displacement of the prostatic apex and also associated pathologies with accuracy, there by assisting the surgeons to the select most appropriate surgical procedure for the patients with obliterative urethral stricture.

\section{Acknowledgements}

Prof. J.Devi Meenal MD, DNB, Professor, Kilpauk Medical College,Chennai. Prof.S. Babu Peter MD,DNB,Professor, Barnard institute of Radiology,Madras Medical College,Chennai. Prof.C.Amarnath MD,DNB,Professor, Stanley Medical College,Chennai.

Prof. N.KailasanathanMD,DMRD, Professor and Director, Barnard institute of Radiology,Madras Medical college, Chennai.

\section{References}

[1]. Tuffier T. Sondeureterale opaque. In: Duplay SE, Reclus P, eds. Traite' de chirurgie. Paris: Masson, 1897; 412-413

[2]. Cunninham J. The diagnosis of stricture of the urethra by Roentgen

[3]. rays. Trans Am AssocGenitourinSurg 1910;5:369-371.

[4]. Dixon CM, McAninch JW. MR imaging of posterior urethral defects and pelvic crush injuries.Urol 1992;148:1162-5.

[5]. Narumi Y, Hricak H,.MR imaging of traumatic posterior urethral injury. injury.radiology.rsna.org/content/188/2/439.

[6]. Peterson AC Webster GD.Management of urethral stricture disease: developing options for surgical intervention. BJU Int 2004;94:971-976.

[7]. Jordan GH, Schlossberg SM. Surgery of the penis and urethra. In: Walsh PC, Retik AB, Vaughan ED Jr, Wein AJ, eds. Campbell's urology. 8th ed. Philadelphia, Pa: Saunders, 2002; 3886-3952.

[8]. Santucci RA, Mario LA, McAninch JW. Anastomotic urethroplasty for bulbar urethral stricture: analysis of 168 patients. J Urol 2002;167:1715-1719.

[9]. Goel MC, Kumar M, Kapoor R. Endoscopic management of traumatic posterior urethral stricture: early results and followup. J Urol 1997; $157: 95$

[10]. MacDonald MF, Santucci RA. Review and treatment algorithm of open surgical techniques for management of urethral strictures. Urology 2005;65:9-15.

[11]. Webster GD, Ramon J. Repair of pelvic fracture posterior urethral defects using an elaborated perineal approach: experience with 74 cases. J Urol 1991;145: 744-748.

[12]. Brandes, S. Invited commentary: authors' response. RadioGraphics

[13]. 2001;21(Spec Issue):S298-S299. 
[14]. Sandler CM, McCallum RW. Urethral trauma. In: Pollack HM, McClennan BL, eds. Clinical urography. $2^{\text {nd }}$ ed. Philadelphia, Pa: Saunders, 2000; 1819-1837.

[15]. MacDiarmid S, Rosario D, Chapple CR. The importance of accurate assessment and conservative management of the open bladder neck in patients with post-pelvic fracture membranous urethral distraction

[16]. defects. Br J Urol 1995;75:65-67.

[17]. Kawashima A, Sandler CM, Wasserman NF, LeRoy AJ, King BF Jr, Goldman SM. Imaging of urethral disease: a pictorial review. RadioGraphics 2004; 24(Spec Issue):S195-S216.

[18]. Koraitim MM. Post-traumatic posterior urethral strictures: preoperative decision making. Urology 2004;64:228-231.(40) 